\title{
Training Program in Engineering Design for Graduate Teaching Assitants
}

\author{
Flavio Firmani, Michael McWilliam, Peter Wild, Michael McGuire, Nikolai Dechev, Colin Bradley \\ Faculty of Engineering, University of Victoria, Victoria BC, Canada \\ Corresponding Author: ffirmani@me.uvic.ca
}

\begin{abstract}
This program is an initiative of the Chair in Design Engineering of the University of Victoria Faculty of Engineering to an NSERC mandate to improve engineering design instruction. To date, there are not enough qualified personnel to support design projects and help students. This problem will be more evident in the upcoming years when the number of undergraduate students will increase and professors will not have the time to guide all the student teams. Therefore, it is imperative the support of highly qualified personnel specialized in design engineering. To this end, a totally new and unique program that trains graduate students to be "Design Teaching Assistants" (DTAs) has been recently launched. In this training program, graduate students learn about engineering design, teaching and mentoring. The program includes a series of workshops, discussion panels and seminars.
\end{abstract}

Keywords: Training program, graduate teaching assistants, engineering design, mentoring, education.

\section{INTRODUCTION}

As recipients of an NSERC Chair in Design Engineering (CDE), the Faculty of Engineering of the University of Victoria is implementing programs to improve the instruction of engineering design in the undergraduate courses. One of these initiatives is a program that prepares Teaching Assistants (TAs) in engineering design, mentoring skills, and teaching.

Graduate students generally do not have any teaching experience in the beginning of their graduate studies and there is a natural state of anxiety when they have to interact with undergraduate students. Training programs for graduate students is common practice in many universities [1-2]. Most of these programs are optional, for professional development, and are offered by a central institution within the universities. However, some studies have shown that the role of TAs in engineering courses is often different from their cohorts in other disciplines [1].
While grading is the primary responsibility for most TAs, engineering TAs are also responsible for the supervision and evaluation of laboratory and course projects. Some Faculties of Engineering have acknowledged these differences and have developed courses for their graduate students [3-5]. In some cases, the training program is mandatory before they are appointed as TAs [4]. Canadian universities, previously recipients of the $\mathrm{CDE}$, have also identified the need of improving design among graduate students. While the University of Manitoba developed a course on design philosophy [6], the University of Waterloo is implementing a teaching workshop based on industrial cases [7]. The UVic Faculty of Engineering is extending this a step further by establishing a unique training program called Design Engineering and Instruction (DE\&I) that prepares the TAs in engineering design (theory and practice), teaching and mentoring.

Design problems are inherently non-deterministic with multiple acceptable solutions [8]. Within engineering courses, teams of undergraduate students are given design problems that they must solve by working together. From this, students are exposed to all the challenges associated with the design process and teamwork. Ideally, the course instructor would guide all the teams through the design process. However, due to the large number of teams there is limited instructor time available for each team. Therefore, it is imperative to have design teaching assistants (DTAs) capable of providing this support.

In order to develop a program to train DTAs, it is critical to understand the function of DTAs in engineering design courses. Ringenberg et al. [9] recognized that a graduate student instructor would occupy four different roles in a senior level design course: mentor, educational psychologist, confidant, and colleague. The mentor role is the most important as it provides guidance to the students through their design project. The educational psychologist role is related to strengthen the teamwork dynamics. The confidant role is to create an atmosphere where the students would feel comfortable to discuss their team problems. The colleague role is referred to advising the undergraduate students how to make their work more interesting. 
Along the same lines, we propose four roles that a DTA would follow, namely mentor (for guidance and assistance with technical problems), educator (for assessment and implementation of design rubrics), adviser (for team management and conflict resolution), and coinstructor (for project coordination and feedback of design project). Notice that Ringenberg's [9] last three roles have been integrated into the adviser role, whereas the educator and co-instructor roles are new roles. Preparing the DTAs for these roles is the focus of the DE\&I.

\section{DESIGN ENGINEERING \& INSTRUCTION}

\subsection{Overview}

The DE\&I program consists of a series of workshops, discussion panels and a series of seminars. Overall, there are three workshops, two discussion panels and six seminars. The workshops and discussion panels took place in three consecutive days, offered for the first time from April 22 to April 25, 2013. Each day was broken into two sessions morning/afternoon and each session was between 2 and $2.5 \mathrm{hrs}$ long. The program is summarized in Table 1.

Table 1: Program of the Workshops.

\begin{tabular}{|l|l|}
\hline Day 1. & $\begin{array}{l}\text { Workshop on Engineering Design I } \\
\text { Workshop on Engineering Design II }\end{array}$ \\
\hline Day 2. & $\begin{array}{l}\text { Workshop on Engineering Design III } \\
\text { Workshop on Mentoring Skills }\end{array}$ \\
\hline Day 3. & $\begin{array}{l}\text { Workshop on Developing Design Projects } \\
\text { Discussion Panels }\end{array}$ \\
\hline
\end{tabular}

The DTAs will attend the seminars between May and June, 2013. The seminars will be presented by guest speakers from industry, experts in engineering design, and experts in organizational behavior management. The program will be offered twice a year.

\subsection{Workshop on Engineering Design}

2.2.1 Overview The Workshop on Engineering Design is meant to provide the fundamentals of engineering design to the DTAs. An effective learning activity for engineering design is for the students to tackle a design challenge; therefore we undertook a thorough process of selecting an appropriate challenge. Design challenges are a great form to expose the design problems and have the students work through the different stages of the design process. However, there are several constraints that we had to consider. The participants of the workshop may have a different level of engineering design background, the time allotted for this workshop is limited, and the discipline could be different (mechanical, electrical, computer science). In addition we decided it was important to give lectures on the design process so the DTAs could pass it on to the undergraduate students.

2.2.2 Learning Objectives In order to select an appropriate activity, we listed the following objectives:

1. Stages of the Design Process The DTAs must understand all the elements that are involved in the stages of the design process. Figure 1 shows a schematic of a generic design process [8]. The first three stages are followed to clarify the problem, generate design concepts and select a particular design, respectively. A single session of the workshop is used to interactively cover each of these three stages. The remaining stages and product management were briefly covered in the final session.

(a) Problem Definition In this stage the engineer must understand the problem that he/she is supposed to solve. In the real world the problem is typically vague and the engineer must ask questions and eventually formulate it as a set of objective criteria and constraints.

(b) Concept Development This is the creative phase of the design. Once the problem is defined the designer generates many different concepts for the solution. In this stage the different concepts should be quite different yet plausible. This ensures that the designer considers every possible solution to the problem.

(c) Design Selection and Assessment This is where the engineer measures the design against the problem definition (not on some subjective opinions) and scores the various concepts to make a selection. Also, the selected designs are assessed by testing built models.

(d) Iteration During the design process, particularly after analyzing the assessment results, the designer learns more about the chosen design and is able to develop a better concept. This cycle of concept development and assessment can also include cycles of problem definition.

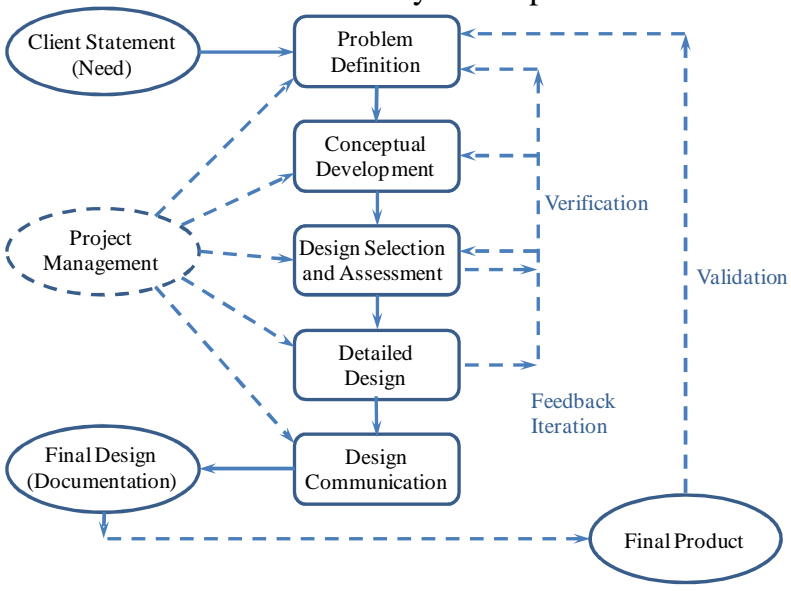

Fig. 1. Five stages of the design process.

2. Open Minded Since design is a creative process that has more than one correct solution the DTAs must be able to accept, understand and evaluate different concepts. 
3. Communication Design requires a special set of communication skills. The DTAs must be able to verbally explain their designs, document their design process in writing and the most unique communication skill is to be able to communicate through diagrams and sketches.

4. Project Coaching The design process is a project that requires management. The designer must recognize the stages of the process and schedule these stages accordingly. The designer must ensure that each stage of the design is completed in a timely manner.

5. Teamwork The designer is most effective when they work within a multi-disciplinary team. The designer must learn to work effectively with other people. This requires conflict management, effective distribution of tasks and coordination of their work.

2.2.3 Workshop Implementation TAs are grouped into teams and they have to solve a simple design problem. In a structured fashion the teams go through the first three stages of the design process. At the beginning of each stage, the workshop coordinators (first two authors of this paper) give a brief lecture of the stage. TAs work for a period of time, after which they present their progress with a short presentation. Coordinators and the other teams provide feedback. Coordinators provide additional methods that help them complete the design stage. This continue until the TAs build a proof-ofconcept model that allow them verify the concept of their design. From these results, they make recommendations for future concepts. Learning Objective: This will teach the TAs about each stage of the design process.

Once during the workshop (after the problem definition stage), the members of all the teams form new teams and continue working on the design process of a previous team. The assumption is that each newly formed team has a different problem definition. With this rearrangement, the coordinators evaluate to what extent the TAs accept the assumptions of the other teams and whether their own assumptions spoil the current design. Learning Objectives: This will teach the TAs to be open-minded and will show them how their assumptions spoil the design process.

Each team is given a couple of minutes to publicly explain their progress. Within the group they will have to communicate design ideas best conveyed through sketches and diagrams. Learning Objectives: This will teach the TAs the communication skills required in the design process.

The various stages of the activity are managed by the workshop coordinators which result in a form of project management that the TAs recognize. Within each stage the TAs have to complete the stages in a limited amount of time and this requires some management by the group itself. Learning Objectives: This will teach the TAs aspect of project management.
The TAs have to work together to complete each stage of the activities. Since the training program attracts TAs from a range of disciplines, TAs will be grouped in different multidisciplinary teams (friends will be separated). Thus they will go through the four stages of teamwork, i.e. forming, storming, norming and performing. Learning Objectives: This will teach the TAs the principles of teamwork.

2.2.4 Criteria for Activity Selection The design objectives for the activity are listed and described below:

1. Customer statement: The description will challenge the TAs in developing the problem statement.

2. Problem statement: The description will lead to different problem statements.

3. Design divergence: A given problem statement should lead to multiple plausible and feasible designs.

4. Evaluation: The solutions can easily be evaluated in the class room.

5. Manufacturing: The chosen design will require to be tested, in the form of a prototype, program, model, or proof of concept.

6. Accessibility: The challenge should be accessible to graduate students from any discipline in engineering.

7. Non-deterministic: The design challenge should avoid problems that are solved with deterministic methods like optimization.

8. Difficulty: The problem should provide some challenge to highly qualified engineers.

9. Team-work: Requires all members of a 3-5 person multi-disciplinary team to work together.

10. Communication: Written, oral and graphical forms of communication are required in the design.

The list of constraints is given below

i. Timing: The TA teams have to reach the stage of testing and evaluating their design concept within 6 hours.

ii. Materials: The solutions can be built with available materials.

iii. Learning Curve: The challenge should not require a skill that the DTA does not possess.

iv. Interference: The activity should not overshadow the learning goals of the workshop.

2.2.5 Selection of Design Activity After discussing a number of activity concepts, the most outstanding nine concepts were scored and evaluated in terms of the above mentioned objectives and constraints. Finally, a final concept was selected: "Systems or technology that improve teaching and learning in large classrooms". This particular concept was the most open-ended problem with a minimal learning curve since graduate students would have learning and teaching experience. Yet before we settled down with this concept we explored some of the problems that the graduate students could identify: 
a) Distribution and/or collection of exams, handouts, and assignments.

b) Communication problems, such as multiple students asking the same questions to the professor by email, delivering announcements to all the students (including the absentees), or scheduling dates at the departmental level (to spread workload through the term).

c) Interaction technology, such as alternatives to commercial clickers, managing a microphone for students in a large auditorium, flexible auditorium seats that allow forming discussion tables with the students behind, or sequential chalkboards that maintain the current and previously used boards always visible.

d) Recognition of students that can be employed for taking attendance or for the identification of students who are participating in class.

We also developed some solutions to these problems and identified ways to build proof-of-concept models.

\subsection{Workshop on Mentoring Skills}

The Workshop on Mentoring Skills was coordinated by the Language and Teaching Centre (LTC) of the University of Victoria. The LTC supports and enhances the teaching improvement efforts of those who instruct at the University of Victoria. Two facilitators from the LTC implemented a role play activity where teams of TAs had to perform a particular scene. Four scenarios were created: teamwork, guidance, project management and ethics. Each team had to identify problems or challenges related to their topic that could arise between the DTAs and the undergraduate students. Teams created a short scene about the challenge. As each team of TAs acted out their roles (as one DTA and a team of undergraduate students) in front of all the other teams, the facilitators froze the scenes and ask each TA to explain the back story of their character. After acting out one time, the DTA received feedback from the other teams and facilitators.

\subsection{Workshop on Developing Design Projects}

Another initiative proposed by the Faculty of Engineering is to develop mini-design projects for those courses that are highly engineering science oriented. Since professors may not have the time to develop these types of mini-projects, we train DTAs to develop their own. The requirement of this activity was to develop a non-existing design project for a course where the participants have been appointed as TAs in the past or are experts in the subject matter. The first task was to identify the course and learning objectives. Once they were defined, the teams had to develop the design miniprojects, establish the design objectives and a suitable strategy for managing the students (e.g. project schedule, expectations, marking rubrics, etc.). Each team presented their mini-projects to other three teams and a workshop coordinator. The other teams and the coordinator provided feedback to improve their design mini-project concepts.

This workshop served as a capstone of the overall workshop (design, management, scheduling, coordination, teaching, etc.). The experience gained by the participants may be valuable as they might be pursuing an academic career. There is also the incentive that if the developed mini-project is suitable (i.e. has valuable learning objectives, improves the quality of the existing courses, does not interfere with other courses and the primary instructor of the course supports it), it can be implemented as part of the course curriculum. It is unlikely that a fully feasible project can be developed within the allotted time $(2.5 \mathrm{hrs})$, instead the expectation is promising projects would be forwarded to the appropriate professor and they would work with the DTA to develop it further.

\section{RESULTS AND DISCUSSION}

\subsection{Engineering Design Learning Outcomes}

From observation, the nineteen TAs who attended the workshop had less design experience than expected. Some of the participants had no formal training. A majority only had the design learned in their undergraduate programs. Teaching design must remain a priority.

The facilitators presented a brief lecture and a set of design methods that would support the next design phase in the activity. When the students started working together on the activity they all used one or more of the tools. Many of the teams reported that these methods were effective during their presentation. Some of the teams came to unexpected results because of these tools. The participants were learning new methods and appreciated the value they brought to the design process.

The use of design methods became a discussion topic in the conceptualization phase. When the teams were asked to come up with multiple plausible and unique solutions, two clear dominant approaches were taken. Three of the five teams started to discuss their ideas immediately and broke the problem down using functional analysis. In general, their concepts were similar, or they rapidly identified a solution and developed it in detail. The other two teams did not discuss, instead each member would privately think of personal concepts. Once all the team members had thought their concepts they shared their ideas. These teams managed to explore the design space as a whole and were able to come up with some unexpected solutions. The difference in the approaches and the outcomes became a point of discussion.

For the most part the teams were quick to adopt the design methods and try them out. However this was not 
the case when it came to testing. In this stage of the activity the teams were supposed to select a concept and perform a simple proof-of-concept test. Overall the teams were reluctant to test and required substantial coaching. Most of the teams wanted to perfect the design selection first. The coordinators had to explain that testing can help to clarify the problem and develop new ideas. A team felt they knew the concept well enough and did not need to test committing the classic mistake of over-confidence. Another team wanted to perform the testing with the same rigor that is expected in research.

There was a problem in the problem definition phase of the activity. The facilitators presented a vague problem definition that was supposed to be open to interpretation. The expectation was that the teams would develop different problem statements that would then be used in subsequent design phases. However all the teams developed a similar problem: feedback. The facilitators had to develop their own problem statements for the next stages. The workshop could be improved by giving a more specific problem statement during the problem definition stage, and then providing different problem definitions for the proceeding stages. The problem definitions that were provided were not fully developed and required revision. This became a learning opportunity on design iteration.

During the Developing Design Project Workshop, the participants worked in eight teams and were able to recognize courses that could include in their curriculum a design project. The teams were able to identify proper learning objectives and even develop management strategies of how to implement the project within the existing courses. However, the majority of the teams were unable to distinguish a conventional project from a design project. Particularly, there was little effort to develop the project based on design objectives.

\subsection{Mentoring Learning Outcomes}

The second objective of the workshop was to develop vital skills for mentoring which included interpersonal, communication leadership and conflict resolution skills. Initially the teams were reluctant to interact with each other and when the teamwork started there was still an adjustment phase. Once the first team activity was completed all other interactive lessons went smoothly.

Overall the participants experienced heavy engagement of teamwork. Throughout the workshop they all worked with four different teams. This way they experienced the stages of group formation several times. Once the participants were comfortable they all communicated their ideas. In the presentations many participants were offering advice to the other teams, exhibiting both communication and leadership skills. Some difficult situations did arise. There were instances of one member of the group taking over, however there were other members in the group that were able to resist and help contain that person. Some conflict did arise as the team members debated their differences and managed to resolve them constructively.

The workshop dedicated to mentoring proved to be very effective. This workshop focused on managing difficult situations. Initially all the groups required substantial coaching to develop a scenario. In most of the scenarios there was a common theme of dysfunctional teams. It was clear that many of the participants were not aware of the full range of problems that could arise in supporting design projects. Interestingly in every one of the four scenarios, the TA who played the role of the DTA was not able to solve the problem. After all the participants provided some suggestions of how to deal with such problems, the scene was re-acted and the DTA was able to do a much better job in solving the problem.

In the end, many of the students reported that they developed some new ideas. Many of the participants were surprised that discrimination is still an issue. Two of them later reported that they became aware of their own discriminatory practices.

\subsection{Overall Impressions}

Overall the students were very enthusiastic about the workshop. In the presentations the students were asking questions, and discussing the content. In all the activities they were motivated to work on the activities. Throughout the workshop the students were giving positive feedback and overall thankful for all our help.

In the feedback one student remarks: "I really enjoyed taking the course, and it was useful. It definitely highlighted some components of design that I had forgotten over the years. I think it's good to have refresher once in a while if you haven't been exposed to these design principles in a long time. The [mentoring workshop] was quite enjoyable, and provided good insight into [teaching] experiences. Both [of the facilitators] really knew the content inside-out, which made it really easy for us to get answers to our questions/problems."

In all sessions of the workshop we failed to complete the activity in the allotted time. In these cases either the activity was cut short or the activity ran into the break. Scheduling one hour long breaks allowed for some flexibility. Concerning the timing another student remarks: "The lecture/slides took up a lot of time, leaving little time left for the design activities, and little time to practice all the tools that were presented in the slides."

Providing mandatory reading material before the workshop would relax the need to present the material in detail. Instead the reading material was provided as an optional resource. When the students were working on the activity they were more concerned with perfecting every stage than progressing through all the stages within the 
allotted time. To counter this, the facilitators for the mentoring workshop would vocalize their progress expectations every 5-10 minutes. This had a positive effect on forcing the students to progress quickly. The technique should be used in the other workshops.

The panel discussion proved to be very valuable for the students. One student remarks: "The panel discussion, especially the one with faculty, was of great value, since this gave us the chance to learn how faculty see our role and how other TA's fill in that role. [I learned] it is important to not directly give answers, but to rather guide students in the design process; sometimes students need to run into problems to understand; if students are experiencing difficulties and/or are unhappy with the situation [I will tell them] 'to [learn how to] deal with that problem now, since your future employer will expect you to be able to handle similar difficulties'; it is of great value to make students think you like their idea ... then from this you can guide them in a different direction."

Another student remarks: "Judging by the response of the professors and the experienced TAs, it seems like DTAs need to focus a lot of energy on conflict resolution and team work"

In the discussion panels the students became noticeably more introverted and were not initiating as much discussion as they were in previous sessions. The moderators were leading the discussion. Having the discussion more structured and asking the panelists to prepare a short discussion would have been helpful.

After the workshop the facilitators were asked to judge each participant on how prepared they are to be a DTA. Overall the participants exhibited satisfactory skills on design but needed more practice to be a strong designer. The participants exhibited stronger mentoring skills. Overall half the attendants demonstrated strong teaching skills. The remainder showed skills that could be improved with a little experience. The facilitators determined that three participants would be strong DTAs that are ready to support projects now. Ten of the attendants showed good skills and would be strong DTAs with some experience. The remaining six showed satisfactory performance, however they would require some further support to develop into strong DTAs. Overall the workshop successfully developed a pool of DTAs capable of supporting design projects.

\section{CONCLUSIONS}

After completing the workshops and discussion panels, we conclude that the TAs exhibited satisfactory skills in design despite not having a previous design formation. Only three TAs showed excellent design skills, while ten showed good skills. The majority would require practice to become successful DTA. All the TAs were enthusiastic about the program and demonstrated strong teaching and mentoring skills. After teaching the program for the first time, the coordinators also learned some of the challenges that have to be address in the future. One in particular is that we overestimated the design background of the TAs and due to the limited time available, we had summarize the design process as a revision; however, it would be more beneficial for the TAs to have some reading material beforehand that will allow them to attend the workshops with some basic preparation in engineering design.

\section{Acknowledgements}

The authors wish to thank all the TAs who participated in this workshop. We also thank the LTC facilitators Cynthia Korpan and Anne Cirillo for their support in the development and coordination of the Workshop on Mentoring Skills. The authors also wish to thank the panelists (faculty and expert TAs) and the guest speakers who have agreed to give presentations for this program.

\section{References}

[1] Torvi, D. A. "Engineering Graduate Teaching Assistant Instructional Programs: Training Tomorrow's Faculty Members," Journal of Engineering Education, vol. 83, no. 4, pp. 376-381, 1994.

[2] Young, S.L. and Bippus, A.M., "Assessment of Graduate Teaching Assistant (GTA) Training: A Case Study of a Training Program and Its Impact on GTAs," Communication Teacher, vol. 22, no. 4, 2008.

[3] Verleger, M. and Velasquez, J., "An Engineering Teaching Assistant Orientation Program: Guidelines, Reactions, and Lessons Learned from a One Day Intensive Training Program," 37th ASEE/IEEE Frontiers in Education Conf., pp.S4G 3-7, (Milwaukee, WI; Oct. 10-13), 2007.

[4] Mark, K.; Thadani, D.R.; Calonge, D.S.; Pun, C.F.; Chiu, P.H., "In-service Teaching Assistant Training (InsTAT) for Engineering and Computer Science Graduate Students in Hong Kong: A Blended-Learning Approach," 41st ASEE/IEEE Frontiers in Education Conf., pp.F2E 1-6, (Rapid City, SD; Oct. 12-15), 2011

[5] Wankat, P. C., and F. S. Oreovicz, "Teaching Prospective Engineering Faculty How To Teach," Journal of Engineering Education, vol. 21, no. 5, pp. 925-930, 2005.

[6] Britton, M.R., "Impacts of the NSERC Chair in Design Engineering at The University Of Manitoba," ASEE 2002 Annual Conference, 9 pp., 2002.

[7] Lambert S. "Integrating Industrial Experience into the Undergraduate Engineering Curriculum Using Case Studies," ICSIT 2012, (Orlando, FL; Mar 27), 6 pp., 2012.

[8] Dym, C.L. and Little, P., Engineering Design: A ProjectBased Introduction. Toronto, ON: Wiley, 2008 ( $3^{\text {rd }}$ ed $)$.

[9] Ringenberg, J., Soloway, E., and Chesney, D., "Curricular Middle Management: The Role of a Graduate Student Instructor in a Senior-Level Design Course," ASEE 2007 Annual Conference \& Exposition, 7 pp., 2007. 